\title{
PILOT - PLANT EXPERIMENTS FOR THE REMOVAL OF THMS, HAAS AND DOC FROM DRINKING WATER BY GAC ADSORPTION- GALATSI WATER TREATMENT PLANT, ATHENS
}

\author{
K.G. BABI ${ }^{1}$ * \\ K.M. KOUMENIDES ${ }^{1}$ \\ A.D. NIKOLAOU ${ }^{1}$ \\ N.S.MIHOPOULOS 3 \\ F.K. TZOUMERKAS 2 \\ C.A. MAKRI ${ }^{1}$ \\ T.D. LEKKAS ${ }^{1}$
}

\author{
${ }^{1}$ University of the Aegean, Department of Environmental Studies \\ University Hill, Mytilene 81100, Greece \\ ${ }^{2}$ EYDAP, 156 Oropou str., Galatsi, Athens, Greece \\ ${ }^{3}$ Technological Educational Institute of Crete \\ Department of Natural Resources and Environment \\ 3 Romanou str., Chania 73133, Crete, Greece
}

Selected from papers presented at the $8^{\text {th }}$ Conference on Environmental Science and Technology, 8 - 10 September 2003, Lemnos, Greece. *to whom all correspondence should be addressed: e-mail: kbabi@env.aegean.gr

\section{ABSTRACT}

A pilot-plant study was carried out with the water supply to Athens water works filtered through a granular activated carbon (GAC) filter- adsorber. The objective of this study was to evaluate the performance of GAC for the removal from drinking water of the two main groups of disinfection by -products (DBPs), trihalomethanes (THMs) and haloacetic acids (HAAs), as well as of dissolved organic matter. The pilot treatment facility is located at the Water Treatment Plant of EYDAP in Galatsi, Athens, and was operated as a rapid gravity filter - adsorber. It was fed with chlorinated water, coming from the overflow of the sedimentation tanks, and operated continuously in parallel with a full-scale sand filter. At regular time intervals water samples were taken from both filters and analysed for THMs, HAAs and DOC. Other parameters were measured too. The operation of the GAC filter-adsorber continued until the GAC adsorption capacity for THMs and HAAs was almost exhausted.

The results of the analyses showed that GAC was more effective in removing the dissolved organic matter than the smaller molecules of THMs and HAAs, fact which is in agreement with the relevant literature. GAC was also proved more effective in removing HAAs than removing THMs. The removal of THMs and the most part of the removal of HAAs and DOC must be attributed to adsorption by GAC, while that of a smaller part of DOC and HAAs may be attributed to biological activity in the filter bed, where chlorine had been totally removed by the catalytic action of the activated carbon surface.

KEYWORDS: THMs, HAAs, DOC, GAC, adsorption, drinking water treatment.

\section{INTRODUCTION}

Chlorine is the most commonly used disinfectant in many water treatment plants. It reacts with the natural organic matter (NOM) in water and pro- 
duces a variety of disinfection by-products (DBPs). Chlorination by-products are formed when chlorine reacts with bromide $\left(\mathrm{Br}^{-}\right)$and natural organic matter in source waters. NOM (arising from decaying vegetation and algae) and bromide (derived from mineral deposits and salt water intrusion) are present in almost all drinking water sources (Nikolaou, 2002; Rook, 1974).

DBP production is strongly dependent on NOM concentration and also on its physical and chemical properties. Bromide plays an important role in determining the relative concentrations of by-product species formed. It has been shown to shift the distribution of some DBPs to more brominated and mixed halogenated species (Cowman et al., 1996; Golfinopoulos et al., 1996; Kampioti et al., 2002; Nieminski et al., 1993; Pourmoghaddas et al., 1993). The two largest classes of chlorination by-products detected (on a weight basis) in treated drinking waters are trihalomethanes (THMs) and haloacetic acids (HAAs) (Arora et al., 1997; Nieminski et al., 1993; Pourmoghaddas et al., 1993; Singer et al., 1995).

The four THMs are chloroform $\left(\mathrm{CHCl}_{3}\right)$, bromodichloromethane $\left(\mathrm{CHBrCl}_{2}\right)$, dibromochloromethane $\left(\mathrm{CHBr}_{2} \mathrm{Cl}\right)$ and chloroform $\left(\mathrm{CHCl}_{3}\right)$. The sum of the concentrations of the four THMs is referred to as total trihalomethanes (TTHMs). The nine bromine- and chlorine- containing HAAs are monochloroacetic acid (ClAA), dichloroacetic acid $\left(\mathrm{Cl}_{2} \mathrm{AA}\right)$, trichloroacetic acid $\left(\mathrm{Cl}_{3} \mathrm{AA}\right)$, monobromoacetic acid (BrAA), dibromoacetic acid $\left(\mathrm{Br}_{2} \mathrm{AA}\right)$, tribromoacetic acid $\left(\mathrm{Br}_{3} \mathrm{AA}\right)$, bromochloroacetic acid (BrClAA), bromodichloroacetic acid $\left(\mathrm{BrCl}_{2} \mathrm{AA}\right)$ and dibromochloroacetic acid $\left(\mathrm{Br}_{2} \mathrm{ClAA}\right)$. In practice, the sum of ClAA, $\mathrm{BrAA}, \mathrm{Cl}_{2} \mathrm{AA}, \mathrm{Cl}_{3} \mathrm{AA}$ and $\mathrm{Br}_{2} \mathrm{AA}$ concentrations is known as HAA5, while the sum of all nine is known as HAA9 (THAAs in this study).

Toxicology studies have shown several DBPs (including THMs and HAAs) to be carcinogenic or to cause adverse reproductive or developmental effects in laboratory animals. Numerous epidemiology studies have suggested an increased cancer risk to individuals who consume or are exposed to chlorinated waters (AWWA, 1990; Magnus et al., 1999; Yang et al., 1998).

Because of the serious health risk which is represented by THMs and HAAs, regulatory action has been taken to control the levels of these DBPs in finished drinking water. The US Environmental
Protection Agency has established maximum contaminant levels for the sum of four THMs and five HAAs at 80 and $60 \mu \mathrm{g} \mathrm{l}^{-1}$, respectively, in the drinking waters (USEPA, 1998b). The Commission of the European Communities has also proposed a Council Directive with parametric values of 40 and $15 \mu \mathrm{g} \mathrm{l}^{-1}$ for chloroform and bromodichloromethane, respectively, and the level of $100 \mu \mathrm{g} \mathrm{l}^{-1}$ for TTHMs (EC, 1998).

Several treatment alternatives have been proposed for the removal of NOM and THMs. Granular activated carbon (GAC) has been of a special interest due to its ability to remove a wide range of compounds such as odor and color causing compounds, NOM, THMs and other toxic compounds. GAC has already been used as a filter-adsorber or a postfilteradsorber in many water treatment plants in Europe and in the USA. However, it was shown that the adsorption capacity of GAC varied widely, depending on the source water which is somewhat unique with respect to daily and seasonal variation in contaminants, background organics, other water quality parameters that can affect adsorption, and the pretreatment given to the water. Isotherm tests or minicolumn tests may provide good reason to anticipate that activated carbon will be a practical solution to a water quality problem, but the question about how GAC will perform on the water in question still remains. Thus, there is the need for on-site pilot studies in order to determine the effectiveness of GAC for the removal of NOM and organic DBPs (AWWA, 1990; Black et al., 1996; Graese et al., 1987; Jacangelo et al., 1995; Lykins et al., 1988).

Previous research on the drinking water of Athens has revealed that the finished water contains organic matter, THMs and HAAs (Golfinopoulos et al., 1996; Golfinopoulos et al., 2001). The objective of this study is to evaluate the performance of GAC for the removal of THMs and HAAs, and dissolved organic matter (DOC, Dissolved Organic Carbon) from the drinking water of Athens. GAC is being used as a sand replacement system, which receives water with the same pretreatment and operates under the same conditions as the existing sand filters (the same hydraulic loading rate and empty bed contact time, EBCT).

\section{MATERIALS AND METHODS Granular Activated Carbon}

Filtrasorb TL-830 (Chemviron Carbon) was used. Its granulometry is $10 \mathrm{X} 20 \mathrm{US}$ mesh, its bed den- 
sity $430 \mathrm{~kg} \mathrm{~m}^{-3}$ (backwashed and drained) and its uniformity coefficient is 1,4 . It is considered to be resistant to abrasion, so it allows repeated backwashing with negligible losses. The quantity of Filtrasorb TL-830 which was used was $13885,5 \mathrm{~g}$.

\section{Pilot-plant operation}

The pilot- plant experiments were conducted in the Water Treatment Plant of Galatsi, Athens (GTP), which receives water from Mornos, Marathon and Yliki water bodies. GTP is of conventional design. Water treatment applied in the Plant includes prechlorination, coagulation, flocculation, sedimentation, rapid gravity sand filtration and postchlorination.

The pilot treatment facility is located at Galatsi Water Treatment Plant. It mainly consists of a rapid gravity GAC filter, operating in parallel with a full-scale sand filter. The GAC filter column is constructed of plexiglass and stainless steel to avoid problems of possible contamination or adsorption of organics from the treated water. It is equipped with a gravity feed system and a totalflow meter before the inlet to the unit to measure the volume of treated water on a continuous basis. It is also equipped for backwashing. Ports are located at different depths on the GAC column. They are connected with either silicon sampling tubes or polypropylene tubes for head loss measurement. The depth of the GAC bed is 1,14 metres, which is about the same as that of the parallel operating sand filter. The volume of the GAC bed is 32,292 1 (1 Bed Volume).

Water coming from the overflow of the sedimentation tanks was passed by gravity through the GAC bed with an almost constant linear velocity of 7,2 m $\mathrm{h}^{-1}$, which was the same as that used in the sand filters of the GTP. The empty bed contact time (EBCT) of the GAC column was 9,5 min. The operation of the GAC filter-adsorber was interrupted by regular backwashing with chlorinated finished water coming from the outlet of the sand filters, when the pressure drop through the filter reached a maximum desirable level. The mean duration of a filtration run was about 29,2 hours and the backwashing rate was about 20-25 m h${ }^{-1}$, so that the GAC bed expansion was approximately $25 \%$.

The operation of the GAC filter continued until the GAC adsorption capacity for THMs and HAAs was almost exhausted.

\section{Sampling and sample preparation}

At regular time intervals water samples were taken with a peristaltic pump through silicon tubing from the inlet, outlet and different depths in the GAC column, as well as from the inlet and outlet of the sand filter operating in parallel. The samples were analysed for THMs, HAAs and DOC. Also, $\mathrm{pH}$, temperature, free residual chlorine, bromide ion, turbidity and SOL-UV absorption were measured. Sampling was performed during 10 filter runs in a time period of 235 days. During the first 6 filter runs samples were taken twice, at the start and at the end of each filter run. The sample preparation and preservation were performed according to Standard Methods (APHA, 1992).

The water samples were analysed for THMs and HAAs in the Water and Air Quality Laboratory of the Department of Environmental Studies of the University of the Aegean. The analysis for DOC was performed in Kiourka Laboratory of EYDAP, while the rest of the analyses were carried out in Galatsi Laboratory of EYDAP.

\section{Analytical Procedure}

Table 1 summarizes the analytical methods used and the respective references.

\section{RESULTS AND DISCUSSION}

The pilot plant was operated for 235 days. Its oper-

Table 1. Analytical Methods used

\begin{tabular}{|c|c|c|}
\hline$\overline{\text { Parameter }}$ & Method & Reference \\
\hline$\overline{T H M s}$ & LLE (with MTBE)-GC-ECD: USEPA method 551.1 & USEPA, $1998 a$ \\
\hline$H A A s$ & LLE (acidic methanol esterification) - GC-ECD & Nikolaou et al., 2002 \\
\hline \multirow[t]{2}{*}{$D O C$} & Persulfate-Ultraviolet oxidation, & \\
\hline & after sample filtration through 0,45 $\mu \mathrm{m}$ & APHA, 1992 \\
\hline SOL-UV absorption & Measured at $254 \mathrm{~nm}$, after sample filtration through 0,45 $\mu \mathrm{m}$ & APHA, 1992 \\
\hline Free chlorine & DPD colorimetric method & APHA, 1992 \\
\hline Bromide & Ion Chromatography & APHA, 1992 \\
\hline Turbidity, Temperature, $p H$ & Standard Methods & APHA, 1992 \\
\hline
\end{tabular}


Table 2. Water parameters measured

\begin{tabular}{|c|c|c|c|}
\hline \multirow[t]{2}{*}{ Water parameter } & \multicolumn{3}{|c|}{ Results } \\
\hline & Mean value & Maximum value & Minimum value \\
\hline Temperature * $\left({ }^{\circ} \mathrm{C}\right)$ & 13,14 & 19,50 & 8,40 \\
\hline$p H^{*}$ & 7,41 & 7,66 & 7,07 \\
\hline$p H^{* *}$ & 7,49 & 7,88 & 7,12 \\
\hline$p H^{* * *}$ & 7,46 & 7,70 & 7,18 \\
\hline Turbidity* (NTU) & 1,78 & 3,26 & 0,93 \\
\hline Turbidity** (NTU) & 0,50 & 0,98 & 0,27 \\
\hline Turbidity*** (NTU) & 0,90 & 2,44 & 0,44 \\
\hline Free $\mathrm{Cl} 2 *\left(\mathrm{mg} \mathrm{l}^{-1}\right)$ & 0,57 & 1,12 & 0,11 \\
\hline Free Cl2 ** $\left(\mathrm{mg} \mathrm{l}^{-1}\right)$ & 0,00 & 0,00 & 0,00 \\
\hline Free Cl2 *** $\left(m^{\prime} l^{-1}\right)$ & 0,51 & 1,00 & 0,08 \\
\hline Bromide $*\left(\mu g l^{-1}\right)$ & 23,50 & 36,00 & 10,00 \\
\hline Bromide ** $\left(\mu g^{-1}\right)$ & 23,20 & 37,00 & 12,00 \\
\hline
\end{tabular}

${ }^{*}$ Influent ${ }^{* *}$ GAC effluent ${ }^{* * *}$ Sand effluent

ation stopped when the GAC adsorption capacity for THMs and HAAs was almost exhausted.

\section{Experimental results and calculations}

Some of the results of the measurements and analyses performed are presented in Tables 2 and 3 .

The effluent values for some parameters, like temperature, $\mathrm{pH}$ and bromide concentration, did not change significantly through the GAC bed or the sand filter (Table 2). The temperature of the influent water varied seasonally (Table 4), while $\mathrm{pH}$ ranged between 7,07 and 7,66, with a mean value of 7,41. Bromide concentration was relatively low. Free chlorine residual concentration in the sand effluent water was a little lower than that in the influent water, while it became zero at the first 20 $\mathrm{cm}$ of the depth of the GAC bed, throughout the study. This fact was caused by the catalytic action of the GAC and was expected (AWWA, 1990).

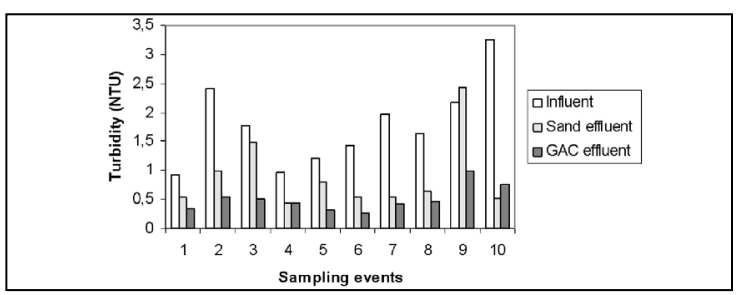

Figure 1: Turbidity of influent, GAC effluent and sand effluent water

Also, the turbidity removal from the influent water by the GAC filter was apparently higher than that by the sand filter operating in parallel, as can be seen in Figure 1.

The influent, GAC effluent and sand effluent concentrations of TTHMs, THAAs and DOC were plotted against the number of bed volumes processed since the start of the operation of the filter-adsorber (breakthrough profiles, Figures 2, 3 and 4).

The percent removal of TTHMs, THAAs and DOC for each sampling event was calculated from the ratio: $\frac{\left(\mathrm{C}_{\text {inf luent }}-\mathrm{C}_{\text {effluent }}\right) 100}{\mathrm{C}_{\text {influent }}}$

The mass of TTHMs, THAAs and DOC removed between two successive sampling events was calculated as follows: First, the area between the curve representing the influent concentration and the bed-volume axis (Figure 2) was calculated and then the area between the curve representing the GAC effluent concentration and the bed-volume axis was also calculated. By subtracting the two areas, which stand for TTHMs influent and GAC effluent mass respectively, the TTHMs mass removed by GAC in that period was calculated. By adding the successive amounts of TTHMs removed, the cumulative removed mass since the start of the operation was calculated. In the same way, the cumulative removed mass of THAAs and DOC was also calculated (Table 4). The breakthrough points for TTHMs, THAAs and DOC were defined as the points where the removal percentage was $20 \%$ and was not significantly increased during the further operation of the GAC filter-adsorber. Complete saturation was defined similarly at $0 \%$ removal.

\section{Breakthrough profiles}

The TTHMs, THAAs and DOC breakthrough profiles are shown in figures 2, 3 and 4 respectively. THMs are small volatile molecules, which are not 
Table 3. TTHMs and THAAs instant concentrations in influent, GAC effluent and sand effluent water during adsorption cycle

\begin{tabular}{|c|c|c|c|c|c|c|c|c|}
\hline \multirow{2}{*}{$\begin{array}{c}\text { Sampling } \\
\text { event }\end{array}$} & \multirow{2}{*}{$\begin{array}{l}\text { Time } \\
\text { since } \\
\text { start } \\
\text { (days) }\end{array}$} & \multirow{2}{*}{$\begin{array}{l}\text { Volume of } \\
\text { processed } \\
\text { water } \\
\text { (1) }\end{array}$} & \multicolumn{3}{|c|}{ TTHMs } & \multicolumn{3}{|c|}{ THAAs } \\
\hline & & & $\begin{array}{c}\text { influent } \\
\left(\mu \mathrm{g} \mathrm{l}^{-1}\right)\end{array}$ & $\begin{array}{c}\text { GAC } \\
\text { effluent } \\
\left(\mu \mathrm{g} \mathrm{l}^{-1}\right)\end{array}$ & $\begin{array}{c}\text { Sand } \\
\text { effluent } \\
\left(\mu \mathrm{g} \mathrm{l}^{-1}\right)\end{array}$ & $\begin{array}{c}\text { influent } \\
\left(\mu \mathrm{g} \mathrm{l}^{-1}\right)\end{array}$ & $\begin{array}{c}\text { GAC } \\
\text { effluent } \\
\left(\mu \mathrm{g} \mathrm{l}^{-1}\right)\end{array}$ & $\begin{array}{c}\text { Sand } \\
\text { effluent } \\
\left(\mu \mathrm{g} \mathrm{l}^{-1}\right)\end{array}$ \\
\hline$S-1$ & 0,66 & 3214,94 & 14,84 & 1,89 & 17,00 & 1,92 & 0,00 & 3,10 \\
\hline$S-2$ & 26,30 & 128758,37 & 16,29 & 2,79 & 23,20 & 11,27 & 0,09 & 9,23 \\
\hline$S-3$ & 48,81 & 238965,51 & 12,22 & 5,96 & 18,35 & 6,51 & 0,43 & 13,52 \\
\hline$S-4$ & 75,60 & 370156,71 & 7,27 & 0,80 & 6,83 & 0,63 & 0,30 & 3,73 \\
\hline$S-5$ & 104,20 & 510146,94 & 9,35 & 7,82 & 10,47 & 19,40 & 4,06 & 17,05 \\
\hline$S-6$ & 111,67 & 546749,48 & 5,58 & 8,52 & 13,51 & 19,76 & 5,52 & 17,96 \\
\hline$S-7$ & 169,51 & 829915,39 & 38,50 & 15,47 & 41,96 & 97,45 & 31,79 & 56,54 \\
\hline$S-8$ & 195,89 & 959057,80 & 32,46 & 17,38 & 39,69 & 31,08 & 15,27 & 18,12 \\
\hline$S-9$ & 217,91 & 1066896,47 & 40,83 & 43,92 & 63,95 & 20,06 & 8,91 & 29,63 \\
\hline$S-10$ & 235,01 & 1150626,35 & 104,29 & 108,12 & 107,05 & 26,05 & 19,79 & 27,74 \\
\hline
\end{tabular}

biodegradable (hydrophobic). THMs are adsorbed by GAC to some extent (AWWA, 1990; Arora et al., 1997). TTHMs breakthrough profile (Figure 2) shows that THMs are removed by GAC adsorption to a satisfactory degree until 31145 Bed Volumes of water have been processed. Thus, the breakthrough occurred after 205 days of continuous operation. After that point (8th sampling event) there is a steep reduction in the effluent water quality and in the percent removal of TTHMs, as it appears in Figure 5. At the breakthrough point it is generally advisable to replace the GAC. The complete saturation of the GAC occurred when approximately 32471 Bed Volumes had passed through the filteradsorber and after about 214 days of operation. At this point the percent removal of TTHMs became zero, while after that it took negative values (Figure 5 ). This was probably caused by desorption of the previously adsorbed THMs onto the GAC (AWWA, 1990). A desorption incident was also noticed at the $6^{\text {th }}$ sampling event (Figure 5)

The TTHMs sand effluent water concentration is generally higher than that of the influent water (Figure 2), which shows that the reaction of THMs formation continues in the sand filter because of the presence of free residual chlorine in the water. However, in the period between the $4^{\text {th }}$ and the $5^{\text {th }}$ sampling event, the TTHMs influent and sand effluent concentrations are closer to each other, probably because of the higher temperature of the water (summer time) and the removal of the THMs, due to volatilisation.

HAAs are soluble in water and biodegradable. They have been reported to be less adsorbable by GAC than THMs due to their hydrophilic character (Arora et al., 1997).

Table 4. Cumulative removed mass of TTHMs, THAAs and DOC by GAC filter- adsorber during adsorption cycle

\begin{tabular}{|c|c|c|c|c|c|}
\hline \multirow{2}{*}{$\begin{array}{c}\text { Sampling } \\
\text { event }\end{array}$} & \multirow{2}{*}{$\begin{array}{c}\text { Temperature } \\
\text { of water } \\
\left({ }^{\circ} \mathrm{C}\right)\end{array}$} & \multirow{2}{*}{$\begin{array}{c}\text { Bed } \\
\text { Volumes } \\
\text { of } \\
\text { processed } \\
\text { water }\end{array}$} & \multicolumn{3}{|c|}{ Cumulative removed mass } \\
\hline & & & $\begin{array}{c}\text { TTHMs } \\
\text { (g) }\end{array}$ & $\begin{array}{c}\text { THAAs } \\
\text { (g) }\end{array}$ & $\begin{array}{c}\text { DOC } \\
(\mathrm{g})\end{array}$ \\
\hline$S-1$ & 10,2 & 99,56 & 0,042 & 0,006 & 2,749 \\
\hline$S-2$ & 11,6 & 3987,33 & 1,701 & 0,828 & 103,160 \\
\hline$S-3$ & 12,6 & 7400,18 & 2,790 & 1,779 & 171,743 \\
\hline$S-4$ & 14,7 & 11462,85 & 3,625 & 2,199 & 233,075 \\
\hline$S-5$ & 19,5 & 15798,00 & 4,186 & 3,296 & 307,269 \\
\hline$S-6$ & 18,8 & 16931,50 & 4,160 & 3,838 & 333,120 \\
\hline$S-7$ & 16,5 & 25700,45 & 7,005 & 15,151 & 556,467 \\
\hline$S-8$ & 10,5 & 29699,68 & 9,466 & 20,412 & 640,825 \\
\hline$S-9$ & 8,6 & 33039,18 & 10,113 & 21,865 & 710,997 \\
\hline$S-10$ & 8,4 & 35632,09 & 9,823 & 22,594 & 768,980 \\
\hline
\end{tabular}


THAAs breakthrough profile (Figure 3) shows that HAAs are removed by GAC to a satisfactory degree until 35632 Bed Volumes of water have been processed. It seems that the breakthrough occurred after a little more than the 235 days of operation of the filter-adsorber (238 days), when 36079 Bed Volumes (calculated) of water had been processed. Thus, the breakthrough for THAAs occurred later than that for TTHMs .

Complete saturation of the GAC was not observed during the 235 days of operation of the GAC filter. It is possible that after the initial period of operation a microbial population grew especially in the depths of the GAC bed which free chlorine did not reach and contributed to the HAAs removal by biodegradation. In this case the removal of THAAs is expected to continue, even after the exhaustion of the GAC adsorption capacity.

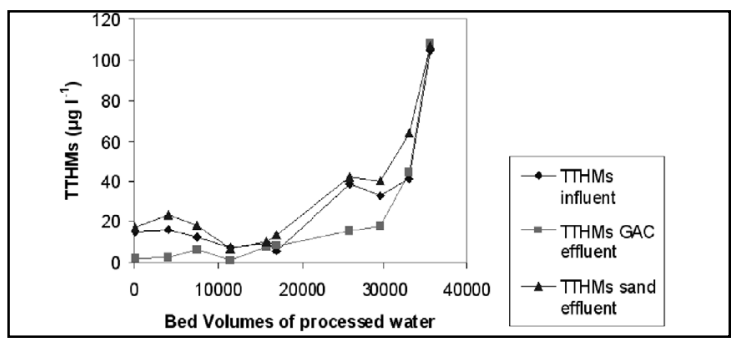

Figure 2: TTHMs breakthrough profile (EBCT: 9,5 min, water flow rate: $7,2 \mathrm{~m} \mathrm{~h}^{-1}$, bed depth: $1,14 \mathrm{~m}$ )

The THAAs concentration in sand effluent water was generally higher than that in the influent water (Figure 3), which indicates that the reaction of HAAs formation continued in the sand filter, as mentioned about THMs. However, the THAAs sand effluent concentration was lower than that of the influent water during the period between the 5 th and the 8th sampling events, when water temperature was higher (Figure 3, Table 4). This may have been caused by microbial growth of chlorine resistant species in the sand filter and subsequent biodegradation of HAAs (Arora et al., 1997).

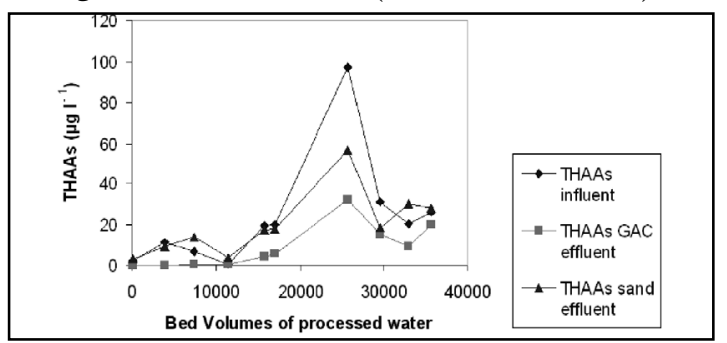

Figure 3: THAAs breakthrough profile (EBCT: 9,5 min, water flow rate: $7,2 \mathrm{~m} \mathrm{~h}^{-1}$, bed depth: $1,14 \mathrm{~m}$ )
As far as DOC is concerned, it is known that DOC parameter includes humic substances which are hydrophobic and non-humic substances which are hydrophilic. Some humic substances are adsorbed by GAC, while non-humic substances are less adsorbable and are more easily removed by biodegradation (AWWA, 1990).

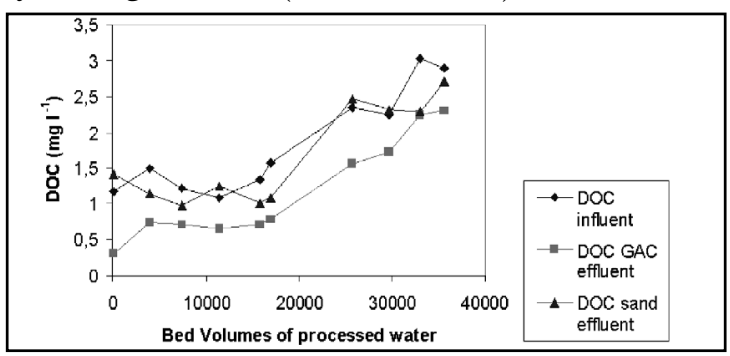

Figure 4: DOC breakthrough profile (EBCT: 9,5 min, water flow rate: $7,2 \mathrm{~m} \mathrm{~h}^{-1}$, bed depth: $1,14 \mathrm{~m}$ )

Figure 5 shows that the DOC percent removal at the start of the operation $(73,4 \%)$ was not as high as that for TTHMs and THAAs, fact that shows that DOC consists of an adsorbable fraction and a non adsorbable one. DOC breakthrough profile (Figure 4) shows a satisfactory DOC removal by GAC until 35632 bed volumes of water have been processed. It seems that the breakthrough for DOC occurred after a little more than the 235 days (237 days) of operation of the GAC filteradsorber, when 35958 bed volumes of water (calculated) had been processed (Figure 5).

It is possible that DOC removal by GAC was partly caused by biodegradation, for the same reasons mentioned about HAAs. In this case it is expected to continue after the exhaustion of the GAC adsorption capacity, depending on the conditions than influence microbial growth.

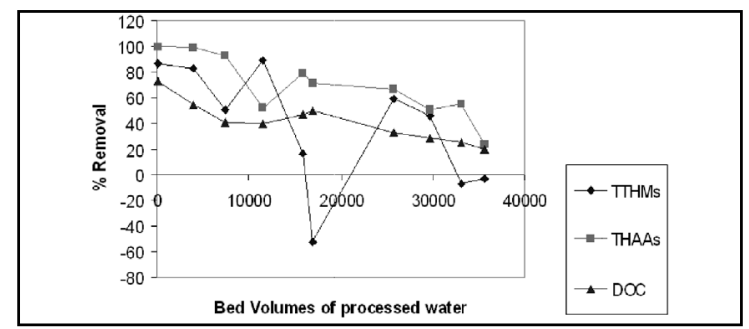

Figure 5: \% Removal of TTHMs, HAAs and DOC by GAC filter-adsorber during adsorption cycle (EBCT: 9,5 min, water flow rate: 7,2 $\mathrm{m} \mathrm{h}^{-1}$, bed depth: $1,14 \mathrm{~m}$ )

The DOC sand effluent concentration was lower than that of the influent water (Figure 4) during some peri- 
ods, as it was observed for THAAs. A reason for this could be again biodegradation in the sand filter.

The TTHMs, THAAs and DOC breakthrough profiles (Figures 2, 3 and 4) and data from Tables 3 and 4 were used to estimate the following:

- The time of operation of the pilot-column at breakthrough.

- The GAC bed life, which is expressed in Bed Volumes of product water to breakthrough.

- The activated carbon usage rate (CUR), which is defined as the mass of activated carbon per unit volume of water treated.

- The GAC capacity to breakthrough, which is expressed as the mass of adsorbate per unit mass of GAC.

The above results concerning breakthrough for TTHMs, THAAs and DOC are respectively:

1) Time of operation: $205,42,237,96$ and 237,16 days

2) GAC bed life: 31145,36079 and 35958 Bed Volumes 3) CUR: 13,806, 11,918 and 11,958 g GAC per $\mathrm{m}^{3}$ of treated water 4) GAC capacity: 0,719 , 1,633 and 55,826 $\mathrm{g}$ of adsorbate per $\mathrm{kg}$ of GAC.

In conclusion, GAC was proved more effective in removing DOC than removing HAAs, and more effective in removing HAAs than removing THMs. The higher breakthrough capacity of GAC for DOC is in agreement with the international research data (Jacangelo et al., 1995; Lykins, 1988). The higher removal of HAAs compared to that of THMs has been attributed to biological activity in the GAC bed by some researchers (Arora et al., 1997).

\section{UV absorption as a surrogate parameter}

UV absorption provides an indication of the aggregate concentration of UV- absorbing organic constituents commonly found in water, such as lignin, tannin, humic substances and various aromatic compounds.

Some researchers have evaluated the use of surrogate parameters as indicators of other water quality parameters that are more difficult to measure and they have shown that UV absorption may have a strong correlation with organic carbon content, color and precursors of trihalomethanes and other disinfection by-products.

As it is easily measured, UV-absorption (at 254 $\mathrm{nm}$ ) has been used in Europe to monitor water plant performance for removals of organic matter (Edzwald et al., 1985; Singer, 1999).

In this study, SOL-UV absorption at $254 \mathrm{~nm}$ was proved to be a useful surrogate measure of the organic content of the chlorinated water after alum coagulation and sedimentation. A strong correlation between SOL-UV absorption and DOC content of the water before or after GAC adsorption was established by regression analysis (Figure 6). This correlation is site specific and holds for the present conditions of water treatment.

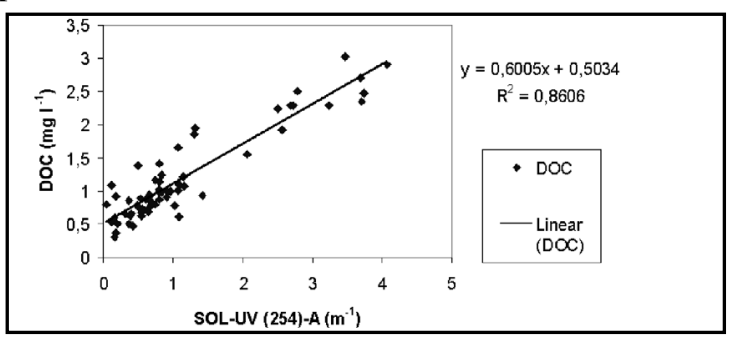

Figure 6: Linear correlation between DOC and SOLUV (254) absorption of water

\section{CONCLUSIONS}

The breakthrough profiles showed that the GAC breakthrough capacity for TTHMs, THAAs and DOC was significant. The breakthrough capacity for DOC was higher than that for THAAs and even higher than that for TTHMs $(55,826 \mathrm{~g}$ DOC, 1,633 $\mathrm{g}$ THAAs and $0,719 \mathrm{~g}$ TTHMs per $\mathrm{kg}$ of GAC). The number of Bed Volumes of treated water at breakthrough for DOC and THAAs was higher than that for TTHMs (35958, 36079 and 31145 BV respectively), while the Carbon Usage Rate (CUR) followed the opposite order, as expected.

The fact that GAC was proved much more effective in removing the dissolved organic matter than the smaller molecules of THMs and HAAs is in agreement with the relevant literature. Also, the removal of THMs and the most part of the removal of HAAs and DOC must be attributed to adsorption by GAC, while that of a smaller part of HAAs and DOC may be attributed to microbial degradation in the filter bed, where chlorine had been totally removed by the catalytic action of the activated carbon surface.

SOL-UV absorption at $254 \mathrm{~nm}$ was proved to be a useful surrogate parameter of the DOC of the chlorinated water after alum coagulation and sedimentation, before or after GAC adsorption. It can be measured rapidly, easily and inexpensively, thus limiting the number of necessary DOC analyses and could be used as an operational control parameter for DOC breakthrough.

Also, the GAC filter efficiency in turbidity removal was higher than that of the sand filter operating in parallel. 


\section{REFERENCES}

American Water Works Association (1990), Water Quality and Treatment, A Handbook of Community Water Supplies, $4^{\text {th }}$ edition, Mc Graw Hill, U.S.A.

APHA, AWWA, WPCF (1992), Standard Methods for the Examination of Water and Wastewater (18 ${ }^{\text {th }}$ ed.), American Public Health Association, Washington, USA.

Arora, H., LeChevalier, M.W., and Dixon, K.L. (1997). DBP occurrence survey, J. AWWA, 89 , 60 -68.

Black, B.D., Harrington, G.W., and Singer, P.C., (1996) Reducing cancer risks by improving organic carbon removal, J. AWWA, 88, 40-52.

Cowman, G.A., and Singer, P.C., (1996) Effect of bromide ion on haloacetic acid speciation resulting from chlorination and chloramination of aquatic humic substances, J. Environmental Science and Technology, 30, 16-24.

Edzwald, J.K., Becker, W.C., and Wattier, K.L., (1985) Surrogate parameters for monitoring organic matter and THM precursors, J. AWWA, 77, 122 -132.

EC (1998), Council Directive 98/83/EC of 3 November 1998 on the quality of water intended for human consumption, Official Journal of the European Communities, L330 dated 5.12.1998, pp. 32-52

Golfinopoulos, S.K., Kostopoulou, M. N., and Lekkas, T. D., (1996) THM formation in the high-bromide water supply of Athens, Journal of Environmental Science and Health, Part AEnvironmental Science and Engineering, A31, 67-81.

Golfinopoulos, S. K., Nikolaou A.D., and Lekkas, T. D., (2001), Disinfection by-products in the drinking water of Athens, Proceeding of the $7^{\text {th }}$ International Conference on Environmental Science and Technology, Syros, Greece, vol A, pp 260 - 267.

Graese, S. L., Snoeyink, V. L., and Lee, R. G. (1987), Granular activated carbon filter- adsorber systems, J. AWWA, 79, 64 -73.

Jacangelo, J.G., DeMarco, J., Owen, D.M., and Radtke, S.J., (1995) Selected processes for removing NOM: an overview, J. AWWA, 87, 64-77

Kampioti, A.A., Stephanou, E.G. (2002) The impact of neutral and acidic disinfection by-products (DBPs) in Mediterranean chlorinated water, Water Research, 36, 2596-2606.

Lykins Jr., B. W., Clark, R. M., and Adams, J.Q., (1988) Granular activated carbon for controlling THMs, J. AWWA, 80, 85-92 .

Magnus P, Jaakkola jjk, Skrondal a., Alexander, J., Becher, G., Krogh, T., Dybing, E.,(1999) Water chlorination and birth defects, J. Epidemiology, 10, 513-517.

Nieminski, E.C., Chaudhuri, S., and Lamoreaux, T., (1993), The occurence of DBPs in Utah drinking waters, J. AWWA, 85, 98-105.

Nikolaou, A.D., Golfinopoulos S.K., Lekkas T.D., (2002) Formation of organic by-products during chlorination of natural waters, Journal of Environmental Monitoring, 4, 910-916.

Nikolaou, A.D., Golfinopoulos, S.K., Kostopoulou, M.N., Lekkas, T.D.,(2002), Determination of haloacetic acids in water by acidic methanol esterification- GC-ECD method, Water Research, 36, 1089-1094.

Pourmoghaddas, H., Stevens, A.A., Kinman, R.N., Dressman, R.C., Moore, L.A., Ireland, J.C. (1993) Effect of bromide ion on formation of HAAs during chlorination, J. AWWA, 85, 82-87.

Rook J.J. (1974) Formation of haloforms during chlorination of natural waters Wat. Treatm. Exam. 23, 234-243.

Singer, P. C., Obolensky, A., and Greiner, A., (1995) DBPs in chlorinated North Carolina drinking waters, J. AWWA, 87, 83-92.

Singer, P. C., (1999) Humic Substances as precursors for potentially harmful disinfection by-products, Water Science Technology, 40, 25-30.

USEPA (1998a), EPA Method 551.1, USEPA, Office of Water, Technical Support Center, Cincinnati, $\mathrm{OH} 45268$.

USEPA (1998b), National Primary Drinking Water Regulations: Disinfectants and Disinfection ByProducts Notice of Data Availability, Office of Ground Water and Drinking Water, http:/www.epa.gov/OGWDW/mdbp/dis.html.

Yang C.Y., Chiu, H.F., Cheng, M.F., Tsai SS, (1998) Chlorination of drinking water and cancer mortality in Taiwan, Environmental Research, 78, 1-6. 